\title{
Accuracy and Reliability of Data in IoT System for Smart Agriculture
}

\author{
Nabilah Binti Omar ${ }^{1}$, Hushairi Bin Zen ${ }^{1 *}$, Nadia Nicole Anak Aldrin ${ }^{1}$, Waluyo ${ }^{2}$, \\ Febrian Hadiatna ${ }^{2}$
}

\author{
${ }^{1}$ Universiti Malaysia Sarawak (UNIMAS), \\ Jalan Datuk Mohammad Musa, 94300 Kota Samarahan, Sarawak, MALAYSIA \\ ${ }^{2}$ Institut Teknologi National (ITENAS), \\ Jl. PKH. Mustopha No.23, Bandung, 40124, INDONESIA \\ *Corresponding Author \\ DOI: https://doi.org/10.30880/ijie.2020.12.06.013 \\ Received 08 April 2020; Accepted 14 June 2020; Available online 02 July 2020
}

\begin{abstract}
This paper presents the design and development of low-cost Internet of Things (IoT) system for remote monitoring of agriculture ecosystem. The aims of the research are to evaluate the accuracy and reliability of data collected and transmitted with developed IoT system and access from remote location. These data are then compared with the readings of the conventional stand-alone sensors or meters. The system is set in the laboratory and utilises low cost microcontroller, sensors, Wi-Fi network communication, cloud storage, mobile and web application. Microcontroller Arduino Uno ATMega328P is used with ESP8266 Wi-Fi module to enable the device to be connected to the Internet. The sensors used in this system are selected base on the plant's growth factor. All data collected from the sensors are sent to the Cloud platform such as ThingSpeak and Blynk. Periodical monitoring is carried out on laptop and mobile phone. The results showed that the data taken from the soil moisture, soil temperature, light intensity, surrounding temperature and humidity are accurate and reliable.
\end{abstract}

Keywords: Remote Monitoring, Smart Precise Agriculture, Internet of Things, Monitor Crop, Sensors Technology

\section{Introduction}

Sarawak is the largest state in Malaysia with $124,499 \mathrm{~km}^{2}$ land area which made up $37.5 \%$ of Malaysia [1]. Despite having huge landmass, Sarawak's agriculture sector is under develop. Agriculture-based food products are mostly imported from the outside, making Sarawak one of the largest food importer [2]. Sarawak is not ready to become food exporter due to low farm productivity [3]. Lack of human labour, continuous use of traditional farming methods and no effective supply chain networks are the major hurdle to the agriculture sector. Current scenario for agriculture sector is based on traditional farming, which is far from sustainable agriculture principle. Traditional farming causes environmental pollution which eventually lowering the farm productivity [2].

To improve agricultural productivity, the crop performance under different growth ecosystems such as soil conditions, soil nutrients level and environment are vital to recognised [4]. As for that reason, farmers must implement new innovative agriculture practise namely as smart agriculture or smart farm. Smart agriculture utilised Internet of Things (IoT) technology. IoT term was first coined in 1999 which describe a system where the internet is connected to the physical world via universal sensors [5]. Internet of Things (IoT) is a hot concept newly emerged that will influence how farmers manage and pursue modern farming. IoT provides automation and wireless communication between devices to devices. IoT is made possible due to the decrease of cost of technologies such as cellular network, smartphones, short range wireless communication, and sensors. IoT carry out smart function that are not able to be performed efficiently by human. 
Real time continuous monitoring, accurate information and automation can be executed reliably with IoT. Basic IoT architecture include microcontroller unit, network connectivity, sensor module, memory and user interface [6]. In farming context, the plant will be embedded with sensors, connected with network connectivity, cloud storage and mobile application.

The objective of this smart monitor system is to develop a simple, inexpensive and reliable system utilising sensor, microcontroller unit, network communication and mobile or web application. From this system, farmers can monitor their crop remotely, collect data from their crop and finally use the data to determine the threshold value which can be used for designing smart agriculture practices.

\section{Literature Review}

Every single aspect of Smart Agriculture is discussed in [7]. The article discusses the key drivers of technology in agriculture, also what are the barriers, major smart agriculture applications, future practices and current technology. From the article, farmer's motivations in implementing IoT in agriculture are to reduce climate effects and to achieve higher yields, optimised resources and automation. Inexpert manpower, expensive, and lack of connectivity coverage are few examples of the barrier in executing IoT in agriculture. Soil condition monitoring, smart irrigation, zero fertiliser waste, pest and disease management are the discussed smart agriculture applications.

Smart farming based on remote monitoring are becoming more famous. The goal of [8] is to create farmenvironment monitoring system using Arduino Yun as microcontroller unit with Wi-Fi connection. Sensing result can be seen on JavaScript-based browsers. Video cameras are installed to view real-time crop growth. This smart environment monitoring system is reliable in terms of safety. The data is safely stored inside localhost and real-time viewing is possible.

In [9] the research aims to design smart micro farm to monitor Algae spirulina growth. It uses a microcontroller, such as Arduino, and sensors to create a real-time monitoring system via the internet to monitor water temperature, ultraviolet intensity, and water turbidity. Sensors used in this research are DS18B20 temperature sensor, ML8511 UV sensor and SEN0189 turbidity sensor. All sensors give voltage output measurement. From the voltage outputs, the readings are then analysed accordingly. This system can perform smart automation accordingly when sensor reading meets requirement.

Project was carried out in [10] to study the smart farm monitoring on environment at paddy warehouse. The prototype of a smart capsule was developed to measure the humidity in paddy bags stored in various locations within a warehouse. The smart capsule used Node MCU ESP8266 microcontroller and the SHT21 humidity sensor to send data to the Blynk server over a Wi-Fi network. This monitoring system can perform systematic data storage and effectively display all data.

IoT-based Smart Garden with Weather Station system, which can be used to monitor the growth of plant every day and predict the probability for raining was introduced in [11]. The system was equipped with a sensors and actuators, where it can be monitored and controlled by using a smartphone. Sensors used in this system are DHT11 temperature and humidity sensor, LDR, soil moisture sensor and barometric pressure module sensor. Values from sensors such as temperature, humidity and barometric pressure are compared with online value. From the comparison, it is assumed that the sensors from this smart garden system are working accurately.

In [12], a new system is implemented for smart farming called 'connected farm'. Connected farm systems provide smartphone application to monitor and control the connected farm. Sensors collected data such as the soil moisture, temperature and carbon dioxide monitoring from the farm. The data can be access through the apps and any issue arise, an alert is sent to the farmer. The apps include farm control. Through farm control, farmers can react to the alert sent. For example, if the soil moisture sensor uploads a value less than a threshold suggested by the knowledge base, farmer can trigger the irrigation system using farm control. Besides that, experienced farmers can share their knowledge and guidance with others. Knowledge such as optimal growth conditions can be easily accessed through the apps.

\section{Methodology}

The methodology section is summarised into four parts. The first part discusses the conceptual design and flow. The second and third part focuses on the hardware and software connection while the final part introduces the farm meter used in this system.

\subsection{Conceptual Design and Design Flow}

Crucial parameters that affect the plant growth are light, water, temperature and nutrients [13]. Water is vital for plant's survival. Water in soil (soil moisture) can affect the nutrient uptake and root's growth. While water vapour in air (humidity), is required for photosynthesis. Beside humidity, light and temperature are also essential for photosynthesis [14]. Therefore, parameters such as light, water and temperature are stressed in the monitoring system.

To monitor the parameters, sensors are put at two places of the plant and categorised as two group. The two groups are surrounding weather and soil conditions. The first group of sensors will be collecting data of surrounding 
weather of the farm. For this group, sensor such as temperature sensor, humidity sensor and light sensor are used. Second group will exclusively monitor soil condition. This group will use sensor such as soil temperature sensor and soil moisture sensor. The conceptual design for this system is shown as in Figure 1.

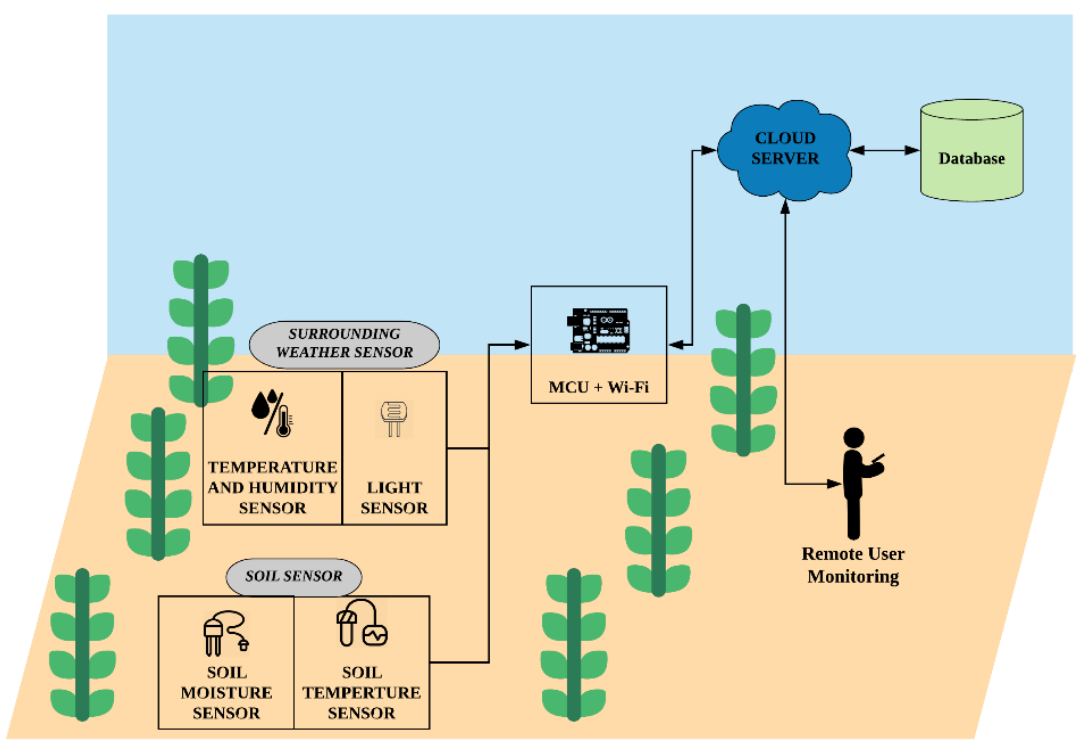

Fig. 1 - Conceptual design

Figure 2 shows the overall system's flow. There will be two sensor nodes for this system. All these sensors will be connected to Arduino Uno ATMega328P with ESP8266 Wi-Fi module. ESP8266 Wi-Fi module is used to connect all sensors online. All the sensors data can be monitor through two platform, ThingSpeak and Blynk. At the same time, all data will be store in database and can be downloaded as a CSV file.

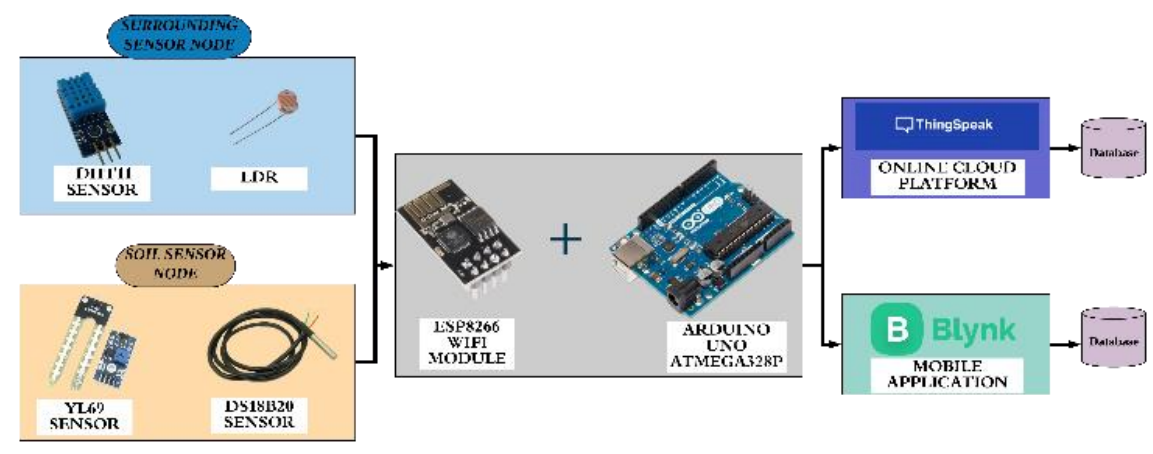

Fig. 2 - System's Flow

\subsection{Hardware}

Figure 3 shows the overall system's hardware connection. Arduino Uno with ATMega328P microchip is a used as microcontroller unit. The Arduino Uno ATMega328P contain two part. The two part are the hardware part and software part. The hardware is the Arduino Uno board. The board has 14 digital input pins and 6 analogue input pins. The software part is the Arduino Integrated Development Environment (IDE) which use language like C programming language [15]. To connect the hardware to the internet and send data from microcontroller to the cloud, ESP8266 Wi-Fi module is used. ESP 8266 connects with the microcontroller using AT commands whereas the microcontroller communicates with the ESP 8266 using UART with definite Baud rate [16]. 


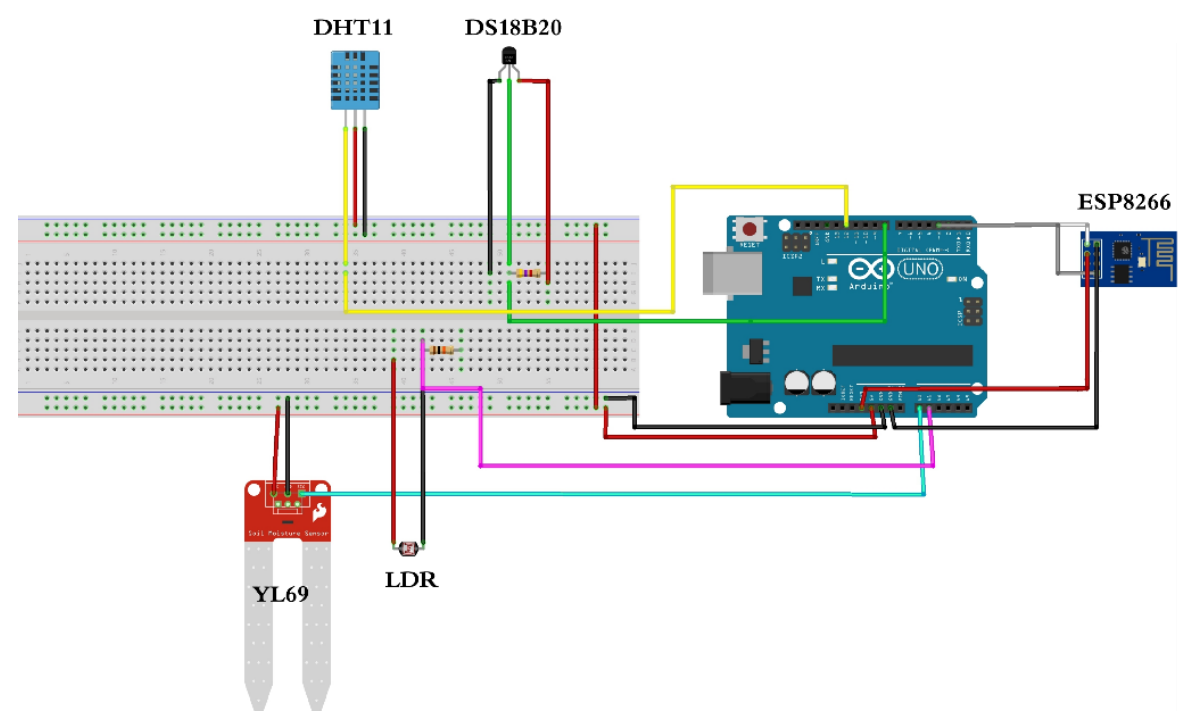

Fig. 3 - Hardware Connection

Two sensor nodes are categorised. Frist node is to monitor soil condition, two sensors are used. The two sensors are DS18B20 temperature sensor with waterproof probe and YL69 soil moisture sensor. YL69 soil moisture measure the resistance of electrical conductivity of water. Moist soil conducts electricity better than dry soil. The higher the conductivity, the lower the resistance. Hence, the reading relies on the water content in the soil [17].

Second node will monitor surrounding condition. Two sensors used are DHT11 and LDR. DHT11 sensor is used to monitor temperature and humidity. LDR is for light intensity monitoring. DHT11 sensor make use a thermistor to sense the temperature and humidity module to measure the humidity [18]

\subsection{Software}

\subsubsection{ThingSpeak}

ThingSpeak is an IoT analytics platform service that allows user to aggregate, visualise and analyse live data streams in the cloud. Instant visualisations of data are posted to ThingSpeak instantly from smart connected devices [19].

For ThingSpeak, user needed to create a channel and select how many chart fields are used. For this system, five fields are created. Using both ThingSpeak and Blynk is easy. From Blynk, a widget call "webhook" is used to "hook" both platforms together. When sensors send data to Blynk, it will simultaneously send data to ThingSpeak. In webhook setting, the ThingSpeak channel API is set to hook both platforms.

\subsubsection{Bylnk}

Blynk is an IoT platform that allows to control, interact and monitor IoT devices such as Arduino, Raspberry Pi, ESP8266 and many more. A graphic interface of the project can be built simply by dragging and dropping widgets [20].

Through this app, all sensors value will be display. Figure 4 shows the application interface in editor mode. All the widget used is as shown in Figure 4. Values such as humidity, soil moisture, temperature and soil temperature are shown in 'super chart' widget while LDR value are shown in "display value" widget. 


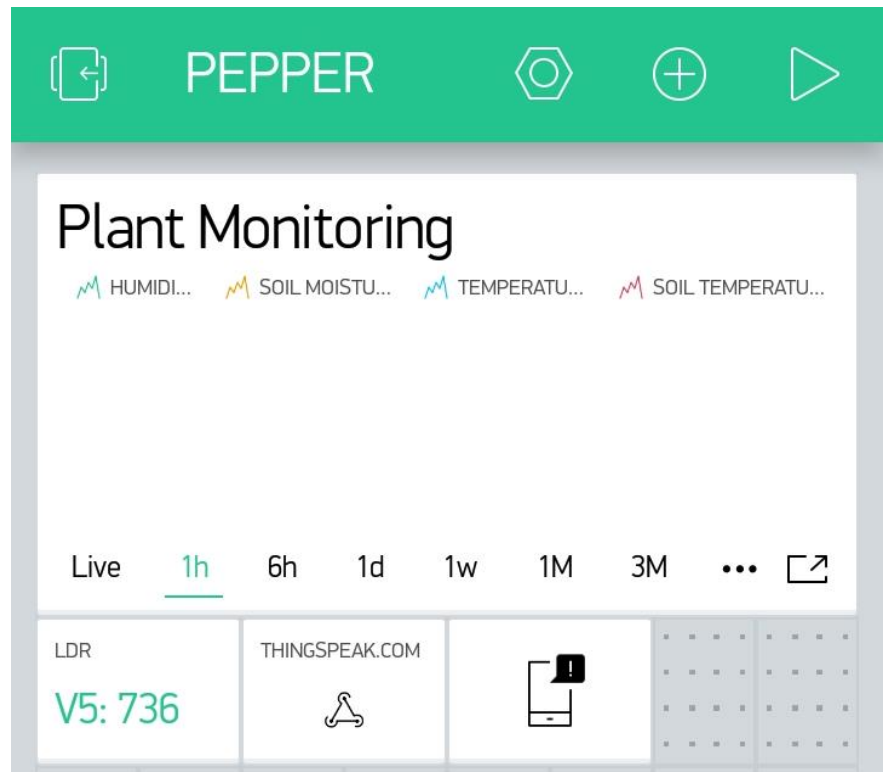

Fig. 4 - Blynk App Interface in Editor Mode

Other widgets used are 'webhook' widget and 'notification' widget. Webhook use to connect both Blynk and ThingSpeak together. Notification widget will help to notify user when hardware device is offline.

\subsection{Farm meter}

All the sensors are calibrated, and the accuracy of the values are compared with generic agriculture meter available as shown in Figure 5. Soil meter can measure three values such as soil moisture, light Lux level, and pH value. Digital thermo-hygrometer measure temperature and humidity level. Digital thermometer with waterproof probe also used to compare soil temperature.
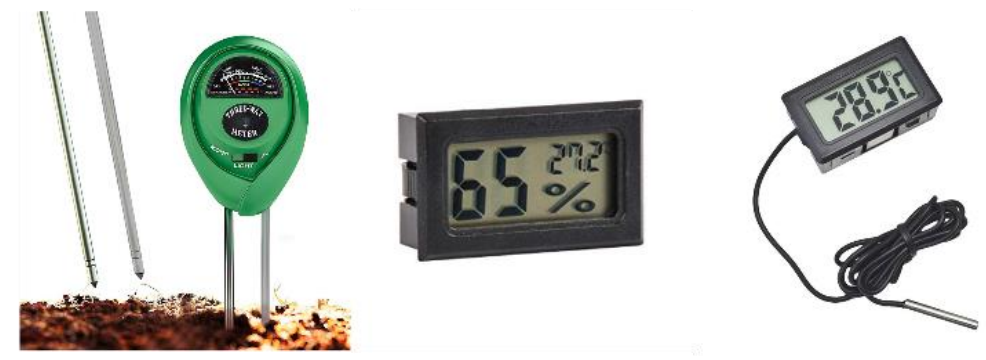

Fig. 5 - Soil meter, digital thermo-hygrometer and digital thermometer respectively

\section{Results and Discussions}

In this section, the device, web and mobile application performances are analysed and summarised in two part. The first part discusses on software's visualisation and application. Second part focuses on accuracy and data reliability.

\subsection{ThingSpeak}

Figures 6 (a), 6(b) and 6 (c) show the visualisation in ThingSpeak. Last field shows the LDR value in numeric display which is to replicate Blynk "display value" widget. 


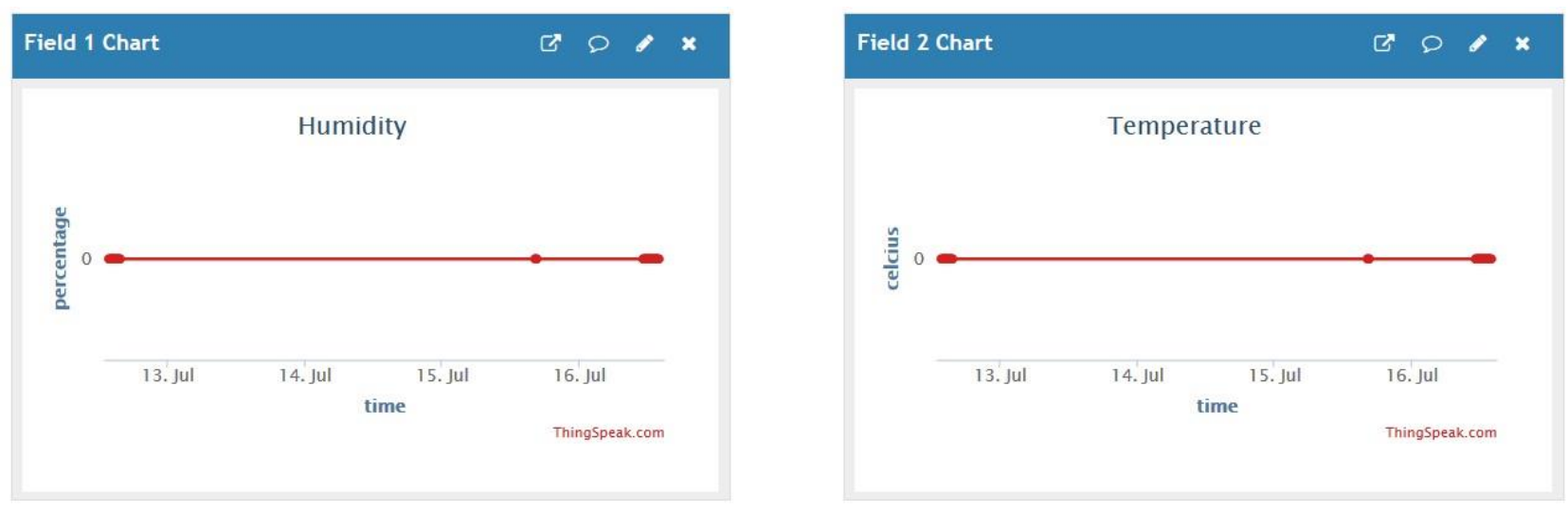

Fig. 6 (a) ThingSpeak Visualisation
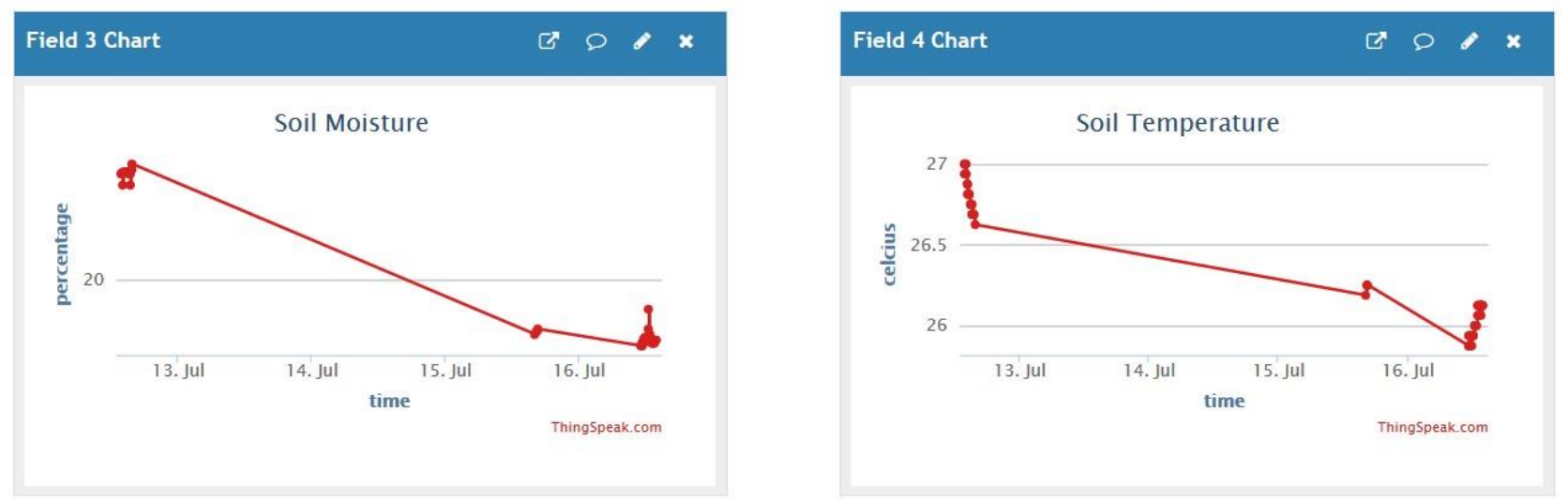

Fig. 6 (b) ThingSpeak Visualisation
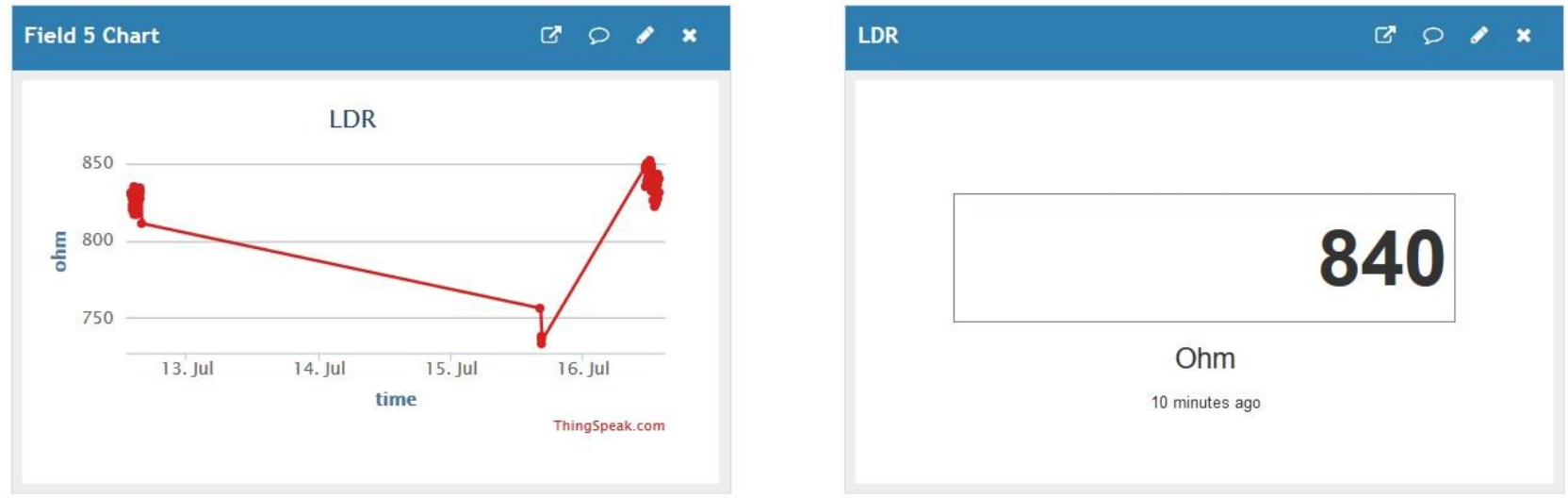

Fig. 6 (c) - ThingSpeak Visualisation 
Data collected from the sensors are stored in ThingSpeak database. In ThingSpeak platform, data is retrieved by exporting csv file from the website. Figure 7 shows the example of the data exported from ThingSpeak. The sensors data is updated with 5 minutes interval.

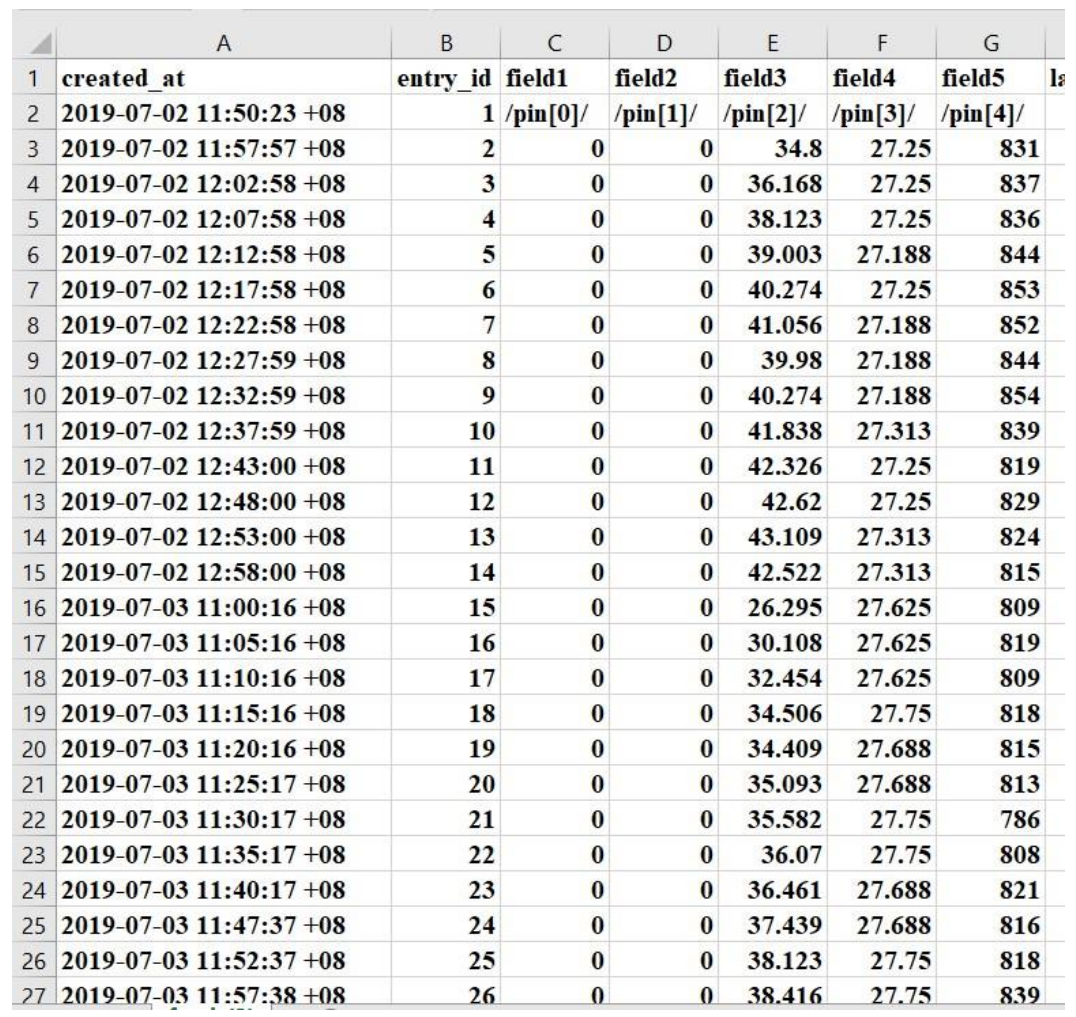

Fig. 7 - The example of data collected in ThingSpeak database

\subsection{Blynk}

The Blynk mobile application was able to display the status of each hardware device as shown in Figure 8 . The "online" status showed that the device work normally while the "offline" status indicated that the device losing Internet connection. A notification would be sent in case any device was disconnected from the system. Once there was an offline device, the Blynk application would send an alert message as shown in Figure 9.

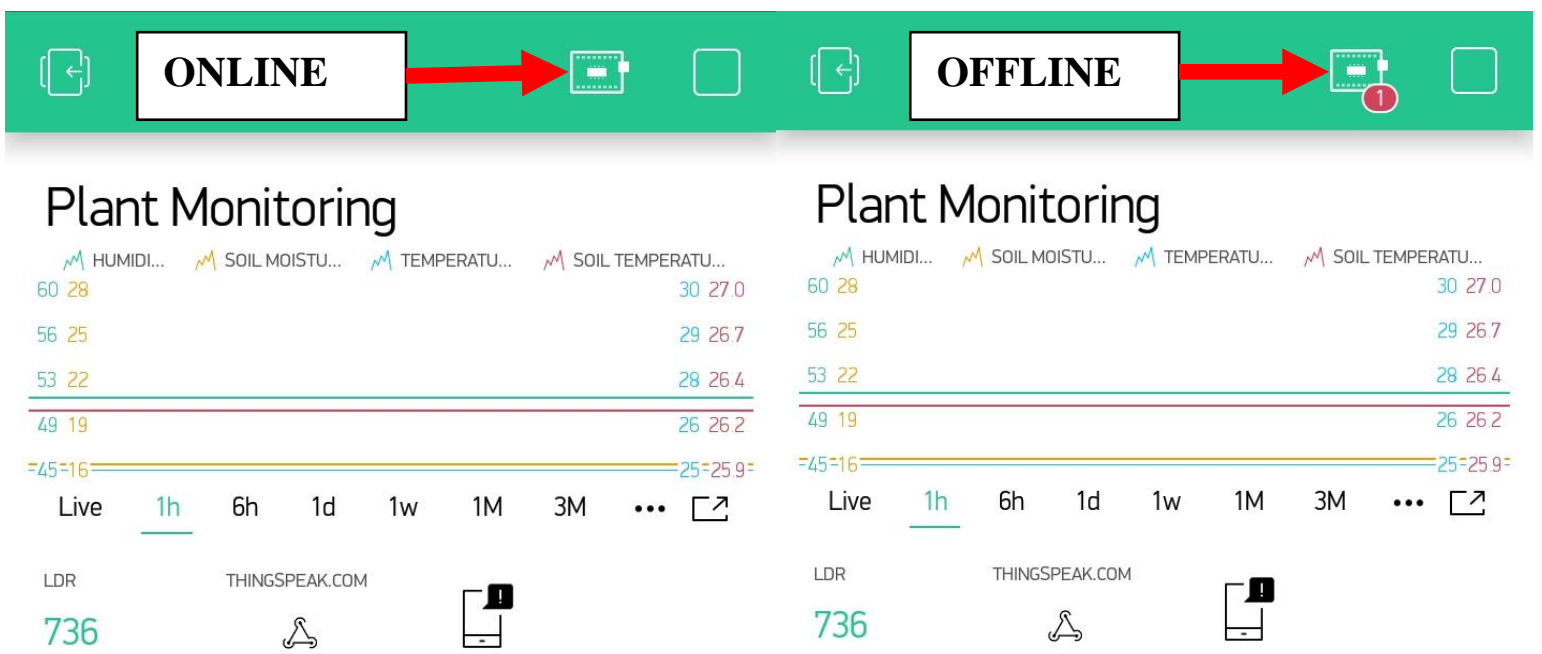

Fig. 8 - Blynk Hardware Status 


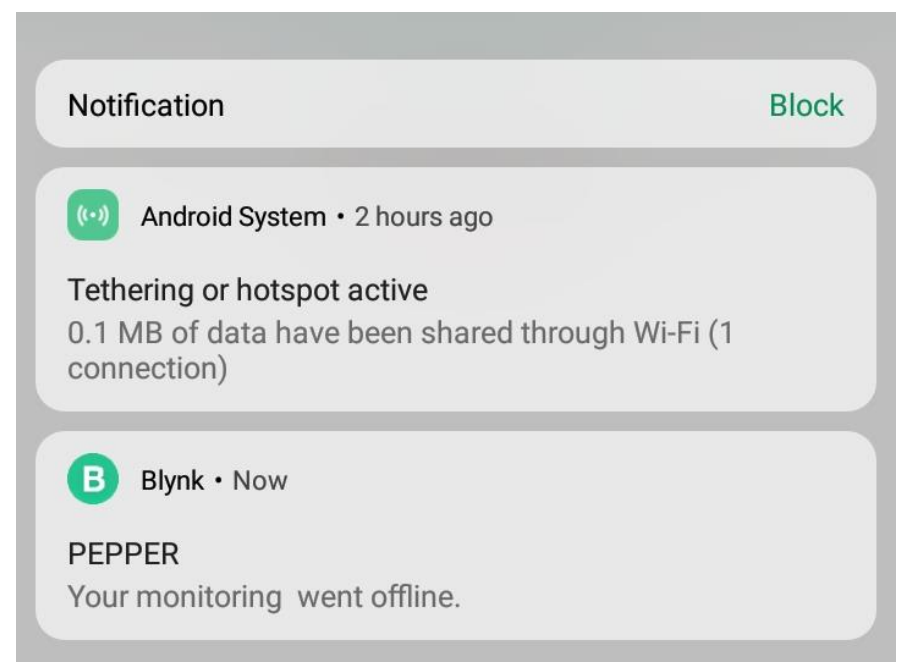

Fig. 9 - Example of Notification system

For Blynk Application, the data from "super chart" widget is emailed by selecting the "export to csv" option. Figure 10 shows the example of the data downloaded from Blynk. Blynk cloud is free to use but limited by data rate. For this system, Blynk records data from sensor with interval of 5 minutes.

\begin{tabular}{|c|c|c|c|c|c|c|}
\hline A & B & C & D & $E$ & $\mathrm{~F}$ & G \\
\hline Epoch time & Time GMT & Time UTC +8 & Humidity (V1) & Soil Moisture (V3) & Temperature (V2) & Soil Temperature(V4) \\
\hline 1562039820 & 2/7/2019 3:57 & $2 / 7 / 201911: 57$ & 57 & 34.8 & 29 & 27.25 \\
\hline 1562040120 & 2/7/2019 4:02 & 2/7/2019 12:02 & 55 & 36.168 & 29 & 27.25 \\
\hline 1562040420 & 2/7/2019 4:07 & 2/7/2019 12:07 & 55 & 38.123 & 29 & 27.25 \\
\hline 1562040720 & 2/7/2019 4:12 & 2/7/2019 12:12 & 58 & 39.003 & 29 & 27.188 \\
\hline 1562041020 & 2/7/2019 4:17 & 2/7/2019 12:17 & 54 & 40.274 & 29 & 27.25 \\
\hline 1562041320 & $2 / 7 / 20194: 22$ & $2 / 7 / 201912: 22$ & 58 & 41.056 & 29 & 27.188 \\
\hline 1562041620 & $2 / 7 / 20194: 27$ & 2/7/2019 12:27 & 53 & 39.98 & 29 & 27.188 \\
\hline 1562041920 & 2/7/2019 4:32 & 2/7/2019 12:32 & 58 & 40.274 & 29 & 27.188 \\
\hline 1562042220 & 2/7/2019 4:37 & 2/7/2019 12:37 & 54 & 41.838 & 29 & 27.313 \\
\hline 1562042520 & 2/7/2019 4:42 & 2/7/2019 12:42 & 58 & 42.326 & 29 & 27.25 \\
\hline 1562042820 & 2/7/2019 4:47 & $2 / 7 / 201912: 47$ & 58 & 42.62 & 29 & 27.25 \\
\hline 1562043120 & 2/7/2019 4:52 & 2/7/2019 12:52 & 56 & 43.109 & 29 & 27.313 \\
\hline 1562043420 & 2/7/2019 4:57 & $2 / 7 / 201912: 57$ & 53 & 42.522 & 29 & 27.313 \\
\hline 1562122800 & 3/7/2019 3:00 & 3/7/2019 11:00 & 62 & 26.295 & 29 & 27.625 \\
\hline 1562123100 & 3/7/2019 3:05 & $3 / 7 / 2019$ 11:05 & 61 & 30.108 & 29 & 27.625 \\
\hline 1562123400 & 3/7/2019 3:10 & 3/7/2019 11:10 & 60 & 32.454 & 29 & 27.625 \\
\hline 1562123700 & 3/7/2019 3:15 & $3 / 7 / 201911: 15$ & 59 & 34.506 & 31 & 27.75 \\
\hline 1562124000 & 3/7/2019 3:20 & $3 / 7 / 201911: 20$ & 59 & 34.409 & 32 & 27.688 \\
\hline 1562124300 & $3 / 7 / 20193: 25$ & $3 / 7 / 201911: 25$ & 60 & 35.093 & 28 & 27.688 \\
\hline 1562124600 & 3/7/2019 3:30 & $3 / 7 / 201911: 30$ & 59 & 35.582 & 29 & 27.75 \\
\hline 1562124900 & 3/7/2019 3:35 & $3 / 7 / 201911: 35$ & 59 & 36.07 & 29 & 27.75 \\
\hline 1562125200 & $3 / 7 / 20193: 40$ & $3 / 7 / 201911: 40$ & 60 & 36.461 & 28 & 27.688 \\
\hline 1562125620 & $3 / 7 / 20193: 47$ & $3 / 7 / 201911: 47$ & 60 & 37.439 & 28 & 27.688 \\
\hline 1562125920 & 3/7/2019 3:52 & 3/7/2019 11:52 & 59 & 38.123 & 29 & 27.75 \\
\hline 1562126220 & 3/7/2019 3:57 & $3 / 7 / 201911: 57$ & 59 & 38.416 & 29 & 27.75 \\
\hline 1562126520 & $3 / 7 / 20194: 02$ & 3/7/2019 12:02 & 59 & 38.416 & 29 & 27.75 \\
\hline
\end{tabular}

Fig. 10 - The example of data collected from Blynk database 


\subsection{Data accuracy and reliability}

The reading differences between the farm meters and sensors are summarised in Table 1 and Table 2 respectively.

Table 1 shows the comparison between farm meter and sensor for soil condition. Soil meter measure soil moisture in ten level and mark as dry (level 1) to wet (level 10) correspondingly. The YL69 soil moisture sensor measure in moisture percentage. From the table, it is only assumed that level 1 is about 10\%. The soil meter read level 3 for all readings while soil moisture sensor reads between 30-36\%. Therefore, there is no absolute way to tell the sensor's accuracy.

The average temperature difference between digital thermometer and DS18B20 is found out to be $\pm 0.5^{\circ} \mathrm{C}$. The difference between the digital thermometer and sensor are insignificant and almost similar. Then it can be assumed that the sensor is working properly.

Table 2 shows the difference between farm meter and sensor for the surrounding weather node. The average temperature difference between digital thermo-hygrometer and DHT11 is $\pm 0.7^{\circ} \mathrm{C}$. The average temperature difference between the thermo-hygrometer and DHT11 is considered small. The small difference is due to DHT11 measures temperature in positive integer which ranging from 0 to $50^{\circ} \mathrm{C}$.

The average humidity difference between digital thermo-hygrometer and DHT11 is $\pm 25 \%$. The reading variance between the sensor and digital thermo-hygrometer reading is due to different humidity measurement range. DHT11 can only measure relative humidity level ranging from $20 \%$ to $80 \%$. However, digital thermo-hygrometer can measure relative humidity between 0 to $100 \%$. For better result and comparison, DHT sensor type DHT22 should be used instead. DHT22 can measure relative humidity between 0 to $100 \%$ which is same with digital thermo-hygrometer.

Table 1 - Reading differences between generic meter and Soil Condition Sensors Node

\begin{tabular}{lcccc}
\hline Date/Time & $\begin{array}{c}\text { Soil Meter, } \\
\text { Soil } \\
\text { Moisture } \\
(\text { Level })\end{array}$ & $\begin{array}{c}\text { YL69 } \\
\text { Sensor, Soil } \\
\text { Moisture } \\
(\%)\end{array}$ & $\begin{array}{c}\text { Digital } \\
\text { Thermo- } \\
\text { Temp }\left({ }^{\circ} \boldsymbol{C}\right)\end{array}$ & $\begin{array}{c}\text { DS18B20 } \\
\text { sensor, } \\
\text { Temp }\left({ }^{\circ} \boldsymbol{C}\right)\end{array}$ \\
\hline $100719 / 1030$ & 3.5 & 36.4 & 27.7 & 27.1 \\
$100719 / 1130$ & 3 & 34.7 & 27.8 & 27 \\
$100719 / 1230$ & 3 & 34.7 & 27.9 & 27.1 \\
$100719 / 1430$ & 3 & 34.4 & 27.9 & 27.2 \\
$100719 / 1530$ & 3 & 34.9 & 28 & 27.4 \\
$100719 / 1630$ & 3 & 34.8 & 28.1 & 27.5 \\
$110719 / 1030$ & 3 & 30.8 & 27.3 & 26.7 \\
$100719 / 1130$ & 3 & 32.9 & 26.1 & 25.8 \\
$110719 / 1230$ & 3 & 32.6 & 26.7 & 26.2 \\
$110719 / 1330$ & 3 & 31.7 & 27.1 & 26.6 \\
$110719 / 1430$ & 3 & 32 & 27.2 & 26.7 \\
$110719 / 1530$ & 3 & 31.4 & 27.3 & 26.7 \\
$110719 / 1630$ & 3 & 31.9 & 27.3 & 26.7 \\
\hline
\end{tabular}


Table 2 - Reading differences between generic meter and surrounding weather sensor node

\begin{tabular}{|c|c|c|c|c|}
\hline Date/ Time & $\begin{array}{c}\text { Digital } \\
\text { Thermo- } \\
\text { hygrometer, } \\
\text { Temp }\left({ }^{\circ} C\right)\end{array}$ & $\begin{array}{c}\text { DHT11 } \\
\text { sensor, } \\
\text { Temp }\left({ }^{\circ} C\right)\end{array}$ & $\begin{array}{c}\text { Digital } \\
\text { Thermo- } \\
\text { hygrometer, } \\
\text { Hum (\%) }\end{array}$ & $\begin{array}{c}\text { DHT11 } \\
\text { sensor, } \\
\text { Hum (\%) }\end{array}$ \\
\hline $100719 / 1030$ & 28.8 & 28 & 73 & 48 \\
\hline $100719 / 1130$ & 29 & 28 & 69 & 45 \\
\hline $100719 / 1230$ & 29.3 & 29 & 69 & 44 \\
\hline $100719 / 1430$ & 29.2 & 28 & 66 & 41 \\
\hline $100719 / 1530$ & 29.6 & 29 & 61 & 38 \\
\hline $100719 / 1630$ & 29.5 & 30 & 62 & 39 \\
\hline $110719 / 1030$ & 27.9 & 28 & 75 & 47 \\
\hline $100719 / 1130$ & 28.1 & 28 & 76 & 48 \\
\hline $110719 / 1230$ & 28.7 & 28 & 79 & 53 \\
\hline $110719 / 1330$ & 28.8 & 28 & 78 & 51 \\
\hline $110719 / 1430$ & 28.6 & 28 & 77 & 52 \\
\hline $110719 / 1530$ & 28.4 & 28 & 77 & 48 \\
\hline $110719 / 1630$ & 28.4 & 28 & 75 & 47 \\
\hline
\end{tabular}

\section{Conclusions}

This monitoring system utilised inexpensive sensor technology with Arduino Uno as microcontroller with open ware platform such as Blynk and ThingSpeak. The monitoring can be easily done by using Blynk mobile application and ThingSpeak web applications. The system is tested with generic agriculture meters and resulted an accurate and reliable system. This monitoring system can help farmer monitor their farm in real time and provide reliable data. Monitoring systems helps farmer to gather data needed to monitor plant's health. All the data collected and store in ThingSpeak database can be further utilised for data analytics.

\section{Acknowledgement}

Author would like to express gratitude to the Sarawak Multimedia Authority (SMA) for the supports and the funding given for this project under Centre of Excellence (CoE) Grant. Also, thanks to Department of Electricals and Electronics, Faculty of Engineering, Universiti Malaysia Sarawak (UNIMAS).

\section{References}

[1] Sarawak State Secretary, "Sarawak Goverment Official Portal," [Online]. Available: https://www.sarawak.gov.my/web/home/article_view/159/176/. [Accessed 26 September 2019].

[2] Islam, M.S., \& Lamoh, M.M. (2017). Advanced Eco-Farming Technology to Achieve Sustainable Agricultural Growth in Sarawak. Kota Samarahan, Sarawak: UNIMAS Publisher.

[3] Pei Pei, G. (2018). Sarawak not ready to export food products on large scale to China. The New Straits Times. [online] Available at: https://www.nst.com.my/news/nation/2018/09/413186/sarawak-not-ready-export-foodproducts-large-scale-china [Accessed 26 Sep. 2019].

[4] Bhagat, M., Kumar, D., \& Kumar, D. (2019). Role of Internet of Things (IoT) in Smart Farming: A Brief Survey. 2019 Devices for Integrated Circuit (DevIC). Kalyani, India.

[5] Ashton, K. (2009). That 'Internet of Things' Thing, RFiD Journal, vol. 22, no. 7, pp. 97-114, July 2009.

[6] Hassan, Q.F. (2018). Internet of Things A to Z: Technologies and Applications. John Wiley \& Sons, Inc. Hoboken, New Jersey.

[7] Ayaz, M., Ammad-Uddin, M., Sharif, Z., Mansour, A., \& Aggoune, E.H.M. (2019). Internet-of-Things (IoT)Based Smart Agriculture:Toward Making the Fields Talk. IEEE Access, vol. 7, p. 33.

[8] Tsai, C.F., Liang, T.W. (2018). Application of IoT Technology in The Simple Micro-Farming Environmental. 2018 IEEE International Conference on Advanced Manufacturing (ICAM). Yunlin, Taiwan.

[9] Ariawan, E., \& Makalew, S.A. (2018). Smart Micro Farm: Sustainable Algae Spirulina Growth. 2018 10th International Conference on Information Technology and Electrical Engineering (ICITEE). Kuta, Indonesia. 
[10] Serikul, P., Nakpong, N., \& Nakjuatong N. (2018). Smart Farm Monitoring via the Blynk IoT Platform: Case Study: Humidity Monitoring and Data Recording. 2018 16th International Conference on ICT and Knowledge Engineering (ICT\&KE). Bangkok, Thailand.

[11] Arbain Sulaiman, N., \& Sadli, M.D.D. (2019). An IoT-based Smart Garden with Weather Station System. 2019 IEEE 9th Symposium on Computer Applications \& Industrial Electronics (ISCAIE). Malaysia.

[12] Minwoo, R., Jaeseok, Y., Ting, M., Il-Yeup, A., Sung-Chan, C., \& Jaeho, K. (2015). Design and Implementation of a Connected Farm for Smart Farming. 2015 IEEE Sensors. Busan, South Korea.

[13] VanDerZanden, A. M. (2008). Extension page: Gardening. Oregon State University, January 2008. [Online]. Available: https://extension.oregonstate.edu/gardening/techniques/environmental-factors-affecting-plant-growth. [Accessed: 5 August 2019].

[14] Dholu, M., \& Ghodinde, K.A. (2018). Internet of Things (IoT) for Precision Agriculture Application. 2nd International Conference on Trends in Electronics and Informatics (ICOEI 2018). Tirunelveli, India, 2018.

[15] Tonny, H.Y.L, Jin Wong, L., \& Shu Ming, T. (2019). Wireless Blood Glucose Device with Database for Health Assessment and Monitoring. 2019 7th International Conference on Smart Computing \& Communications (ICSCC). Malaysia.

[16] Tonny, H.Y.L, Jin Wong, L., \& Raymond, M. (2019). IoT Fitness Device with Real Time Health Assessment and Cloud Storage. 2019 7th International Conference on Smart Computing \& Communications (ICSCC). Malaysia.

[17] Puranik, V., Ranjan, S.A., \& Kumari, A. (2019). Automation in Agriculture and IoT. 2019 4th International Conference on Internet of Things: Smart Innovation and Usages (IoT-SIU). Ghaziabad, India.

[18] Bhadani, P., \& Vashisht, V. (2019). Soil Moisture, Temperature and Humidity Measurement using Arduino. 2019 9th International Conference on Cloud Computing, Data Science \& Engineering (Confluence). Noida, India.

[19] “Learn More About ThingSpeak," [Online]. Available: https://thingspeak.com/pages/learn_more. [Accessed: 22Apr-2019].

[20] "What is Blynk?" [Online]. Available: https://subscription.packtpub.com/book/application_development/ 9781788995061/1 ch01lvl1sec10/what-is-Blynk. [Accessed: 22-Apr-2019]. 